\title{
Lymphoma development in Bax transgenic mice is inhibited by Bcl-2 and associated with chromosomal instability
}

\author{
JJ Luke ${ }^{1}, \mathrm{Cl}$ van de Wetering ${ }^{1,2}$ and CM Knudson ${ }^{\star, 1,2,3}$ \\ 1 Department of Pathology, The University of lowa Roy J. and Lucille P. Carver \\ College of Medicine, lowa City, lowa, USA \\ 2 Molecular Biology Program, The University of lowa Roy J. and Lucille P. Carver \\ College of Medicine, lowa City, lowa, USA \\ ${ }^{3}$ Immunology Program, The University of lowa Roy J. and Lucille P. Carver \\ College of Medicine, lowa City, lowa, USA \\ * Corresponding author: CM Knudson, Department of Pathology, 200 Hawkins \\ Drive, 3160 C ML, lowa City, IA 52242, USA. Tel: 319-335-8147; Fax: 319- \\ 356-0331; E-mail: c-knudson@uiowa.edu
}

Received 23.5.02; revised 19.9.02; accepted 6.12.02

Edited by D Altieri

\begin{abstract}
$B a x$ is a $B c l-2$ family member that promotes apoptosis but has paradoxical effects on lymphoma development in p53deficient mice. To better understand the mechanism of Baxinduced lymphoma development, the effect of Bax levels, p53 status and $\mathrm{BCl}-2$ coexpression on lymphoma development were determined. In addition, DNA content and cytogenetics were performed on young (premalignant) Lck-Bax mice as measures of genetic instability. Bax promoted lymphoma development in p53-deficient mice in a dose-dependent manner. Bax expression also led to lymphoma development in both $p 53+1-$ and $+/+$ animals. Ploidy analysis in mice prior to the onset of overt thymic lymphomas demonstrated that Lck-Bax transgenic mice were more likely to be aneuploid and demonstrate increased chromosome instability. With tumor progression, aneuploidy increased and Bax expression was maintained. Importantly, coexpression of Bcl-2 delayed lymphoma development in Lck-Bax transgenic mice. These data support a model in which increased sensitivity to apoptosis leads directly to chromosome instability in developing $T$ cells and may explain a number of paradoxical observations regarding $\mathrm{Bcl}-2$ family members and the regulation of cancer. Cell Death and Differentiation (2003) 10, 740-748. doi:10.1038/ sj.cdd. 4401233
\end{abstract}

Keywords: apoptosis; Bax, oncogenesis; chromosomal instability; $\mathrm{BCl}-2$

Abbreviations: PCR, polymerase chain reaction; CV, coefficient of variation; $\mathrm{CIN}$, chromosomal instability.

\section{Introduction}

The Bcl-2 family contains a number of related genes that are critical regulators of apoptosis. ${ }^{1}$ The family can be divided into those that inhibit (Bcl-2, Bcl-x, etc.) and those that promote cell death. Those that promote apoptosis can be further characterized as multidomain members (Bax, Bak, Bok) and BH3-only family members based on the extent of homology with $\mathrm{Bcl}-2^{2}$ The $\mathrm{Bcl}-2$ family appears to regulate apoptosis through effects on mitochondria. Antiapoptotic members preserve mitochondrial function and prevent the release of mitochondrial proteins such as cytochrome $c$, Smac/Diablo and AIF, thereby preventing caspase activation and DNA degradation, two hallmarks of apoptosis. ${ }^{3}$ The ability of $\mathrm{Bcl}-2$ to act upstream of caspases and preserve mitochondrial function may contribute to its more potent oncogenic activity relative to other antiapoptotic genes that act downstream such as by inhibition of caspases. ${ }^{4}$ The mechanism by which $\mathrm{Bcl}-2$ prevents the release of mitochondrial components remains controversial, but $\mathrm{Bcl}-2$ appears to prevent the formation or opening of a large mitochondria channel that involves proapoptotic family members and/or the voltage-dependent anion channel. ${ }^{3}$

Recent studies have demonstrated that the BH3-only Bcl-2 family members act upstream of the multidomain members Bak or Bax to disrupt mitochondria function and release cytochrome $c .^{5,6}$ Furthermore, the main function of $\mathrm{Bcl}-2$ or $\mathrm{Bcl}-\mathrm{x}$ may be to prevent $\mathrm{BH}$-only family members from 'activating' Bax or Bak and releasing proapoptotic mitochondria components. ${ }^{7}$ Regardless of the precise mechanism, $\mathrm{Bcl}-2$ is clearly an important mediator of oncogenesis. This is perhaps best illustrated by the involvement of $\mathrm{Bcl}-2$ in the $t(14: 18)$ translocation follicular B-cell lymphoma ${ }^{8-10}$ and has been further demonstrated in transgenic mice. ${ }^{11,12}$ Furthermore, a number of findings implicate the loss of function of the proapoptotic family member Bax in oncogenesis. ${ }^{13-18}$ The Bax gene is inactivated in human colon cancer of the microsatellite mutator phenotype ${ }^{19}$ and Bax-deficient cells appear resistant to cell death following activation of the Trail receptor pathway. ${ }^{20}$

Thus, a number of lines of evidence demonstrate that decreased apoptosis because of alterations in the $\mathrm{Bcl}-2$ family can promote oncogenesis. However, other studies demonstrate paradoxical affects of Bcl-2 family members on oncogenesis. For example, expression of $\mathrm{Bcl}-2$ delays mammary tumor formation in dimethylbenz(a)anthracene treated mice ${ }^{21}$ and hepatocellular carcinoma in c-myc transgenic mice. ${ }^{22}$ Studies of human colon cancer ${ }^{23-27}$ and breast cancer ${ }^{28}$ have demonstrated that $\mathrm{Bcl}-2$ expression is associated with improved survival. For Bax, increased expression in transgenic mice is associated with increased apoptosis and a paradoxical acceleration in lymphoma 
development in p53 -/- mice. ${ }^{29}$ In human cancer, increased Bax expression has been associated with an increase risk of relapse in childhood acute lymphocytic leukemia ${ }^{30}$ and decreased survival in diffuse large B-cell lymphoma. ${ }^{31}$ Therefore, the outcome of $\mathrm{Bcl}-2$ family expression on cancer is complex and may involve regulation of cellular processes other than apoptosis. Alterations in cell proliferation have been proposed to account for the paradoxical effect of $\mathrm{Bcl}-2$ on oncogenesis. ${ }^{21,22}$ However, to date these studies are largely correlative and fall short of proving causation.

The current study demonstrates that aneuploidy is an early and frequent result of expression of Bax and provides an alternative explanation for the paradoxical effects of $\mathrm{Bcl}-2$ family members on oncogenesis. Specifically, $\mathrm{Bcl}-2$ family members may influence oncogenesis through regulation of chromosome stability. This complements and extends pre-

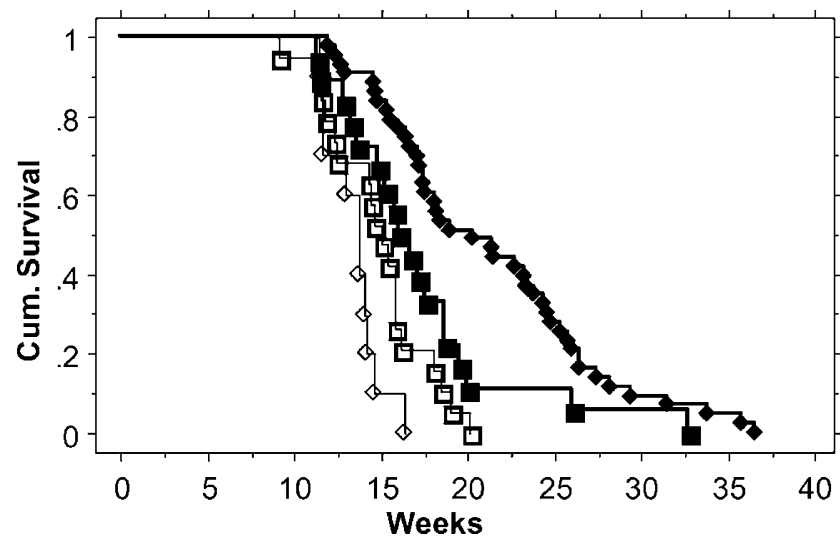

Figure 1 Additive effect of Bax on tumor development in p53-deficient mice. Kaplan-Meier survival plot of $p 53-1-$ mice ( $)$, and $p 53-1-$ mice expressing Lck-Bax $1(\mathbf{\square})$, Lck-Bax38 $(\square)$ or both Lck-Bax38 and Lck-Bax $1(\diamond)$ are shown. Lck-Bax1 $\quad(P=0.0211), \quad$ Lck-Bax38 $\quad(P=<0.0001) \quad$ and $\quad$ Lck-Bax38/1 $(P=<0.0001)$ all had significantly decreased survival relative to control ( $p 53$ $-/-)$ mice. Furthermore, the Lck-Bax38/1 had significantly decreased survival when compared to Lck-Bax1 $(P=0.0027)$ and Lck-Bax38 $(P=0.0472)$ alone. The data from the single transgenics have been previously published ${ }^{29}$ vious data demonstrating that chromosome instability is frequently associated with increased apoptosis.

\section{Results}

\section{Tumor development in Lck-Bax transgenic mice}

Lck-Bax transgenic mice accelerate lymphoma development in p53-deficient mice. These paradoxical findings were true for two transgenic lines ( 1 and 38 ) derived from distinct vectors with differences in the $3^{\prime}$ untranslated region of the cDNA. ${ }^{29}$ This difference has allowed us to determine if the effects of Bax on lymphoma development are additive without requiring homozygous expression of a single transgene. The rate of spontaneous lymphoma development in Lck-Bax38/1 double transgenic $p 53-/-$ mice was determined. When compared to the p53-deficient mice alone, the Lck-Bax38/1 double transgenic animals developed lymphoma at an accelerated rate (Figure 1). These differences were also true when they were compared only to littermate controls that were included in the study (data not shown). Furthermore, when compared to our previous results with the single transgenics, ${ }^{29}$ the LckLck-Bax38/1 double transgenics developed lymphoma at a faster rate than either Lck-Bax1 or Lck-Bax38 alone demonstrating quantitative effects of Bax on tumor development (Figure 1).

\section{Lck-Bax38/1 promotes lymphoma in $p 53+/-$ and $+/+$ mice}

Although Lck-Bax38 or Lck-Bax1 accelerated tumor development in p53 - /- mice, they were not sufficient to accelerate tumor development in p53 +/+ mice (data not shown). However, a number of Lck-Bax38/1 double transgenic mice that were not $p 53$ deficient were found to be sick and many died from thymic tumors at a relatively young age ( $<1$ year). Therefore, the rate of tumor development in Lck-Bax38/1 double transgenic mice with functional $p 53$ was determined. Both Lck-Bax38/1-p53 +/- or p53 +/+ mice had markedly decreased survival (Figure $2 a, b)$ secondary to an increase in
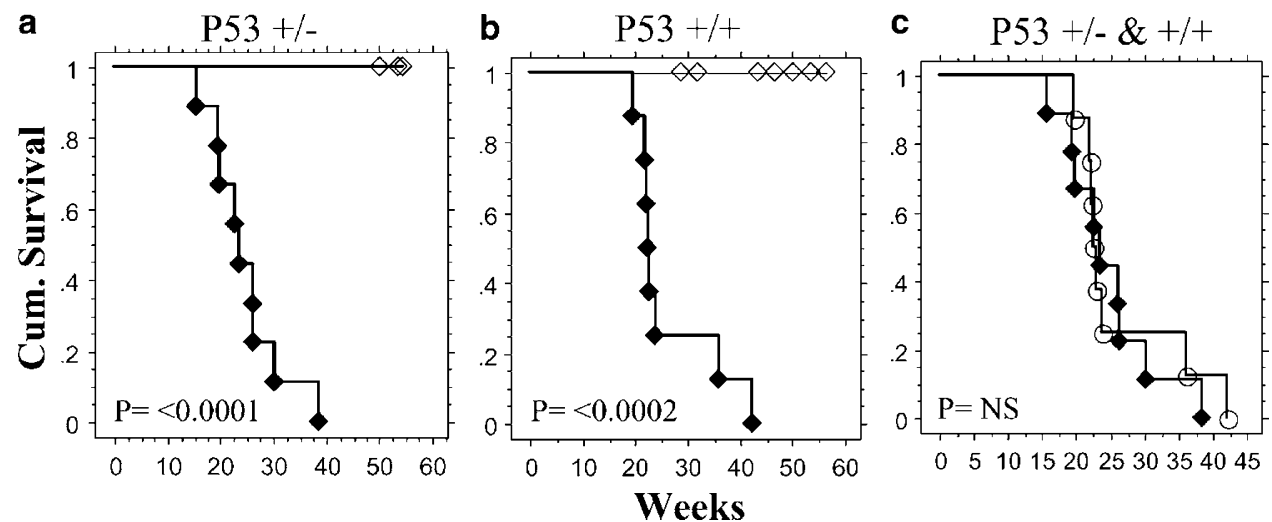

Figure 2 Lck-Bax38/1 double transgenic mice develop tumors independent of $p 53$ deficiency. Lck-Bax38/1 transgenic mice $(\bullet)$ on either a $p 53+/-(\mathbf{a})$ or $+/+(\mathbf{b})$ background were followed for overall survival and compared with negative littermates that were matched for $p 53$ status $(\diamond)$. Lck-Bax38/1 significantly decreased survival in $p 53+/-(\mathbf{a})$ and $p 53+/+$ mice $(\mathbf{b})$ relative to control animals that all survived. The time at which the control mice were censored is indicated by an open diamond $(\diamond)$. Control mice were killed when they reached 1 year of age as described in Materials and Methods. (c) Lck-Bax38/1 tumor formation in $p 53+1-(\bullet)$ and $p 53+/+$ mice $(O)$ mice were not significantly different $(P=0.7825)$ 
Table 1 Increased coefficient of variation of diploid cells in Lck-Bax mice

\begin{tabular}{lcccc}
\hline & Neg & Bax1 & Bax38 & Bax38/1 \\
\hline CV mean & 1.687 & 2.294 & 2.224 & 2.661 \\
$P$-value (versus Neg) & & 0.001 & 0.005 & 0.0001 \\
STD & 0.472 & 0.547 & 0.618 & 0.318 \\
$N$ & 21 & 15 & 15 & 14 \\
\hline
\end{tabular}

thymic lymphomas. Surprisingly, the rate of tumor development was similar between $p 53+/+$ and $p 53+/-$ mice, suggesting that loss of function of $p 53$ may not be the ratelimiting step in lymphoma development of Lck-Bax38/1 mice that contain functional $p 53(+/-$ or $+/+)$ (Figure 2c). These results demonstrate that overexpression of Bax promotes thymic lymphoma development in mice with intact $p 53$.

\section{Aneuploidy in Lck-Bax-p53 - I- mice}

Lck-Bax transgenic mice demonstrate increased thymocyte proliferation which may explain the accelerated lymphoma development. ${ }^{29}$ However, the total number of cycling cells in Lck-Bax mice was not increased because of lymphopenia from the increased apoptosis. ${ }^{29}$ In the process of performing these studies on cell proliferation, the G0/G1 diploid peak demonstrated an increased coefficient of variation (CV) in Lck-Bax transgenic mice (Table 1). One explanation for the widened peak may be altered DNA content because of increased chromosomal instability. Chromosomal instability is observed in many types of tumors and has been described as an enabling characteristic of tumor cells allowing them to acquire the many genetic changes necessary for oncogenesis. $^{32}$ If high levels of Bax promote chromosomal instability, this would provide an alternative explanation for the accelerated tumor formation in Lck-Bax mice. To determine if Bax promotes chromosomal instability, DNA content analysis was performed on young Lck-Bax-p53 -/- mice using propidium iodide staining. Lck-Bax-p53 -/- mice frequently demonstrated more than one near diploid peak, suggesting that an aneuploid population is present in these mice (Figure 3a). Of note, using this relatively insensitive measure of aneuploidy, $\sim 56 \%$ of young Lck-Bax mice were found to be aneuploid (mice with overt thymic lymphomas were excluded) while only $11 \%$ of control p53-deficient mice were aneuploid (Table 2). Importantly, the development of an aneuploid population appears to precede overt tumor development based on the fact they are frequently observed in animals with reduced cellularity (Figure 3b). Cytogenetics performed on the thymocytes from a Lck-Bax mouse confirmed the presence of an aneuploid population in one of these animals (Figure $3 c$ ).

\section{Aneuploidy in Lck-Bax-p53 control mice}

Given that Bax expression was able to induce thymic lymphomas independent of p53 (Figure 2), Lck-Bax38/1 transgenic animals that were $p 53+/-$ or $+/+$ were also examined for DNA content using propidium iodide staining. For these animals, aneuploidy was infrequently detected. This may be because of elimination of aneuploid populations by functional $p 53$ at a point prior to their expansion and detection using DNA content analysis. Nonetheless, in some p53 +/and $+/+$ animals, aneuploid populations were identified and this was seen in animals with a very small thymus (less than 2 million cells) (Figure 4). This demonstrates that aneuploidy is seen in Lck-Bax transgenic mice with functional p53.

\section{Aneuploidy and Bax expression in tumors from Lck-Bax transgenic mice}

If Bax expression directly causes lymphoma development and chromosome instability, expression of Bax would be maintained in tumors from these animals. To test this prediction, lysates of thymic lymphomas from control and Lck-Bax transgenic mice were probed for Bax expression. As expected, Bax expression was increased in tumors from Lck-Bax-positive mice relative to control thymus or tumors from p53-deficient mice with or without $\mathrm{Bcl}-2$ expression (Figure 5a). In addition, the extent and diversity of aneuploid cells is increased in the tumors from Lck-Bax transgenic mice (Figure 5b). These data support a direct and intrinsic role for Bax in lymphoma development in Lck-Bax transgenic mice.

\section{$\mathrm{Bcl}-2$ antagonizes tumor formation in Lck-Bax38/1 mice}

Despite their antagonist function related to the susceptibility of cells to apoptosis, Bax and Bcl-2 are both able to promote thymic lymphoma development. To examine whether these genes would cooperate in thymic lymphoma development or would be antagonistic, the rate of lymphoma formation in mice positive for both Lck-Bax and Lck-Bcl-2 was determined. The presence of the Lck- $\mathrm{BCl}-2$ transgene significantly delayed tumor development in Lck-Bax38/1 double transgenic mice (Figure 6). This was true for both $p 53-/-$ and $p 53+/-$ animals. This data demonstrate that lymphoma development from overexpression of $\mathrm{Bax}$ is delayed by coexpression of $\mathrm{BCl}-$ 2. This is most remarkable in the $p 53+1-$ mice where the control $p 53+/-$ mice get tumors relatively late ${ }^{33}$ in comparison with Lck-Bax38/1 double transgenic (Figure 2). In these animals $\mathrm{Bcl}-2$ dramatically delays tumor formation with the $50 \%$ survival time going from $\sim 6$ months to $>1$ year (duration of the study) in the mice coexpressing $\mathrm{Bcl}-2$.

\section{Discussion}

The demonstration that human Bax can be a transcriptional target of p53 led to a model where Bax is a downstream effecter of $p 53$-dependent apoptosis. ${ }^{13}$ As $p 53$ is the most frequently mutated gene in human tumors, this makes Bax a strong candidate for a tumor suppressor. A number of studies in mice and humans support this hypothesis and suggest that Bax expression inhibits cancer formation. In animal studies, Bax-deficiency potentiates tumors development in SV40 TAg mice ${ }^{15,16}$ and facilitates $\mathrm{E} 1 \mathrm{~A}^{34}$ transformation of fibroblasts. Studies of human malignancies have also implicated $B A X$ as an important tumor suppressor. For example, in colorectal cancer, ${ }^{19}$ gastric carcinoma, ${ }^{35}$ and acute lymphoblastic leukemia ${ }^{36}$ frameshift mutations in $B A X$ have been reported. 
a
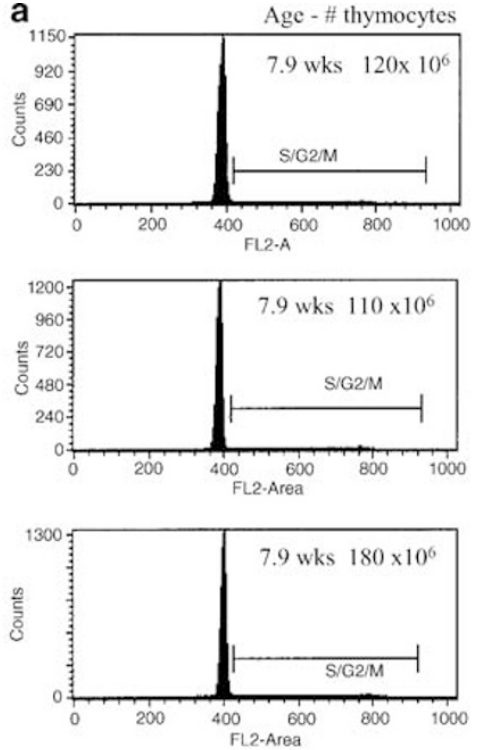

b

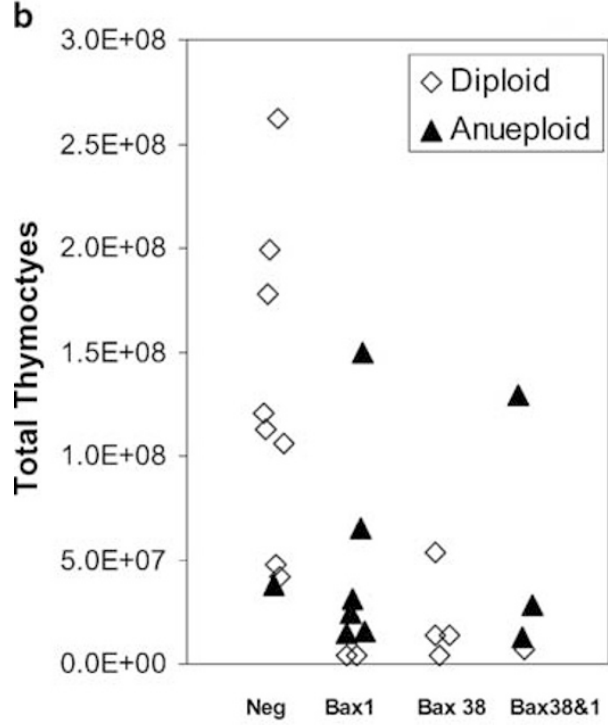

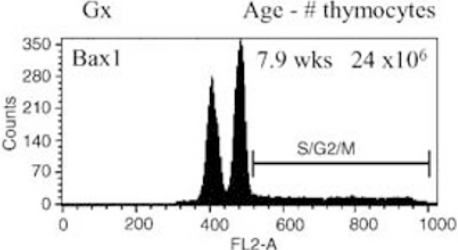
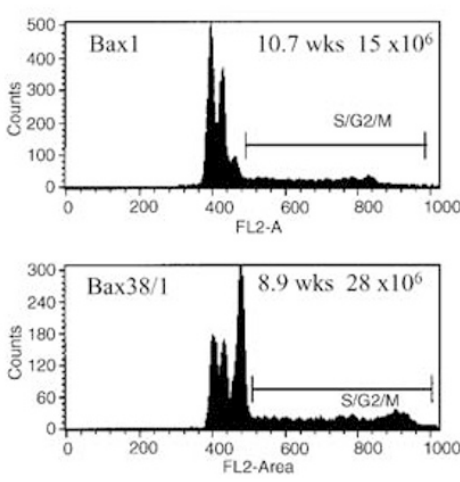

C

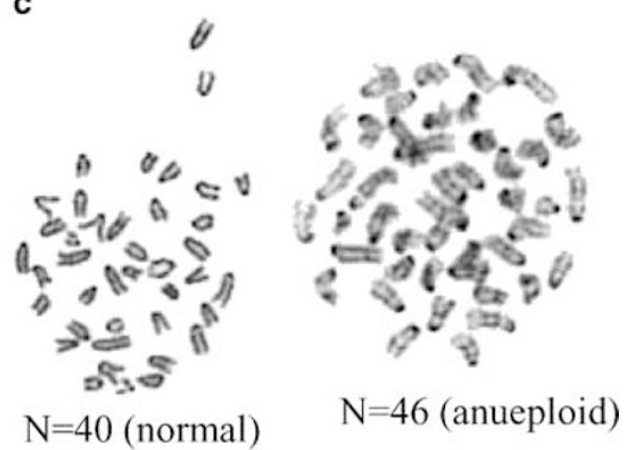

Figure 3 Aneuploidy in Lck-Bax-p53 - / - mice. (a) Shown are examples of DNA profiles from p53 deficient mice without (left) and with (right) the Lck-Bax transgene. Multiple abnormal peaks are readily observed in the Lck-Baxtransgenic mice. The age of each animal and the total number of thymocytes are indicated in the upper righthand corner of each histogram (b) Using the assay illustrated in (a), p53-deficient mice of the indicated Lck-Bax genotype were determined to be either diploid (open diamonds) or aneuploid (filled triangles) and this was plotted versus the total number of thymocytes. Animals with obviously enlarged thymi were excluded from this data and that described in Table 2. (c) Cytogenetic analysis of freshly isolated thymocytes from a 8.9-week-old Lck-Bax38/1-p53-deficient animal (panel A, lower right) is indicated. Both normal and abnormal populations were observed

Table 2 Increased aneuploidy in Lck-Bax mice

\begin{tabular}{lccc}
\hline Lck-Bax & \#Aneuploid & \# Normal & Percentage \\
\hline Neg & 1 & 8 & $11.1 \%$ \\
Lck-Bax38, 1 or Both & 9 & 7 & $56.25 \%$ \\
\hline
\end{tabular}

$P=0.0405$ by two-sided Fisher exact test

In colon cancer cell lines homozygous deletion of Bax promotes resistance of cell to chemotherapeutic agents and nonsteroidal anti-inflammatory drugs. ${ }^{17}$ Mutations in Bax have been described in a number of human hematopoietic tumor cell lines ${ }^{36}$ as well as directly from gastrointestinal cancer. ${ }^{37}$ Retrospective studies of human malignancies have examined the relation between BAX expression by immunohistochemistry or immunoblotting and clinical outcome. As expected if Bax is a tumor suppressor, reduced expression of $\mathrm{BAX}$ is associated with a worse clinical outcome in ovarian cancer, ${ }^{38}$ metastatic breast adenocarcinoma, ${ }^{39}$ and squamous cell carcinoma. ${ }^{40}$ Analogously, increased expression of BAX has been associated with a better prognosis in squamous cell carcinoma ${ }^{41}$ and acute myeloid leukemia. ${ }^{42}$

In contrast, other studies have found a paradoxical effect of Bax on tumor formation. For example, increased Bax levels were associated with a higher rate of relapse in childhood 

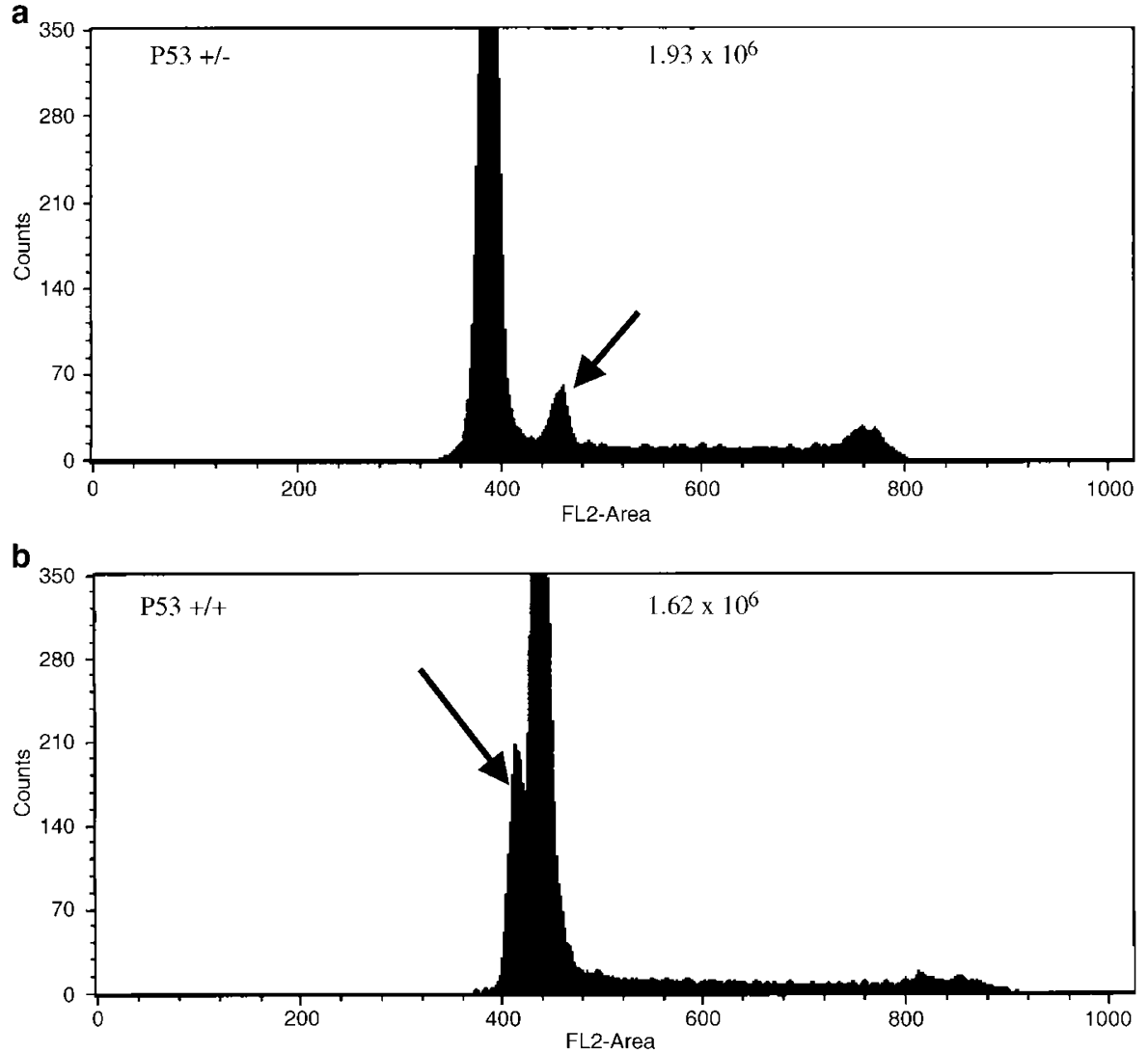

Figure 4 Bax-induced aneuploidy in mice with functional p53. DNA content analysis on thymocytes was performed on an 8-week-old Lck-Bax38/1-p53+/- (a) and a 31-week-old Lck-Bax38/1-p53+/+ (b). The total number of thymocytes isolated is indicated. For (a), when gated the small aneuploid peak represented $7.8 \%$ of the events while the diploid peak represent $76.9 \%$. The data indicate an aneuploid population in the animal that totaled fewer than 400000 cells

acute lymphocytic leukemia. ${ }^{30}$ In non-Hodkins lymphoma, increased Bax levels were associated with decreased patient survival. ${ }^{31}$ In mice, Bax deficiency was unable to accelerate spontaneous tumor development or tumor development in p53 - /- mice, while overexpression of Bax accelerated the development of thymic lymphomas in $p 53-1-$ mice $^{29}$ As discussed in the introduction, $\mathrm{Bcl}-2$ also has been found to have paradoxical effects on oncogenesis. ${ }^{23-28}$ Taken together, these studies suggest that the effects of Bcl-2 family members on de novo tumor formation, susceptibility to treatment and progression are complex and a simple model in which inhibition of apoptosis (by increased Bcl-2 or decreased Bax) accelerates tumor development or progression may not always apply (Figure 7a).

Several possibilities may explain these paradoxical findings regarding $\mathrm{Bax}$ and $\mathrm{BCl}-2$ on tumor progression. In our initial studies, we found that Bax expression increased proliferation of thymoctyes ${ }^{29}$ and others have reported that Bax increases proliferation of $\mathrm{T}$ cells following Con A stimulation. ${ }^{43}$ These observations are complemented by a number of studies that demonstrate that $\mathrm{Bcl}-2$ inhibits proliferation of $\mathrm{T}$ cells, ${ }^{44-46}$ fibroblasts $^{45}$ and IL-3-dependent hematopoietic cell lines. ${ }^{47}$ Although cell cycle regulation is a tantalizing prospect for mediating the oncogenic function of Bax and the antioncogenic function of $\mathrm{Bcl}-2$, the results reported here, that chromosomal instability is an early consequence of Bax expression, provides an alternative and perhaps more likely explanation for the paradoxical acceleration of lymphoma development in mice overexpressing Bax.

As carcinogenesis is a multistep process that requires multiple mutations, recent investigators proposed that cells must acquire genomic instability as an enabling characteristic of tumor cells. ${ }^{32}$ Genetic instability occurs at many levels including chromosome translocations, subtle sequence instability (sometimes termed microsatellite), gene amplification or chromosomal instability (CIN). ${ }^{48} \mathrm{~A}$ number of genes involved in colon cancer are important in DNA mismatch repair and result in microsatellite instability interest. ${ }^{48}$ Similarly, chromosomal translocations are frequently associated with lymphoma and leukemia. However, chromosomal instability or CIN is the most common type of genetic instability and is observed in nearly all types of tumors. ${ }^{48}$ One could argue that $\mathrm{CIN}$ is a result of and not a cause of transformation. However, many colon cancers from patients with defects in DNA repair (microsatellite instability) frequently do not have CIN. ${ }^{49}$ Consistent with CIN being causative in our model, aneuploidy is a frequent and very early manifestation of high expression of Bax.

Despite the nearly ubiquitous presence of $\mathrm{CIN}$, the pathways leading to CIN during oncogenesis are poorly understood. p53-deficient cells frequently demonstrate CIN, however, it does not appear that $p 53$ deficiency is sufficient 
a

\begin{tabular}{|c|c|c|c|c|c|c|c|c|c|}
\hline Sample & $\mathrm{N}$ & $\mathrm{T}$ & $\mathrm{T}$ & $\mathrm{T}$ & $\mathrm{T}$ & $\mathrm{T}$ & $\mathrm{T}$ & $\mathrm{T}$ & $\mathrm{T}$ \\
\hline Bcl-2 & - & - & - & - & - & - & - & + & + \\
\hline Bax & - & 38 & $38 / 1$ & $38 / 1$ & $38 / 1$ & $38 / 1$ & - & - & - \\
\hline P53 & $+/-$ & $-/-$ & $+/+$ & $+/-$ & $-/-$ & $+/-$ & $-/-$ & $-/-$ & $-/-$ \\
\hline
\end{tabular}
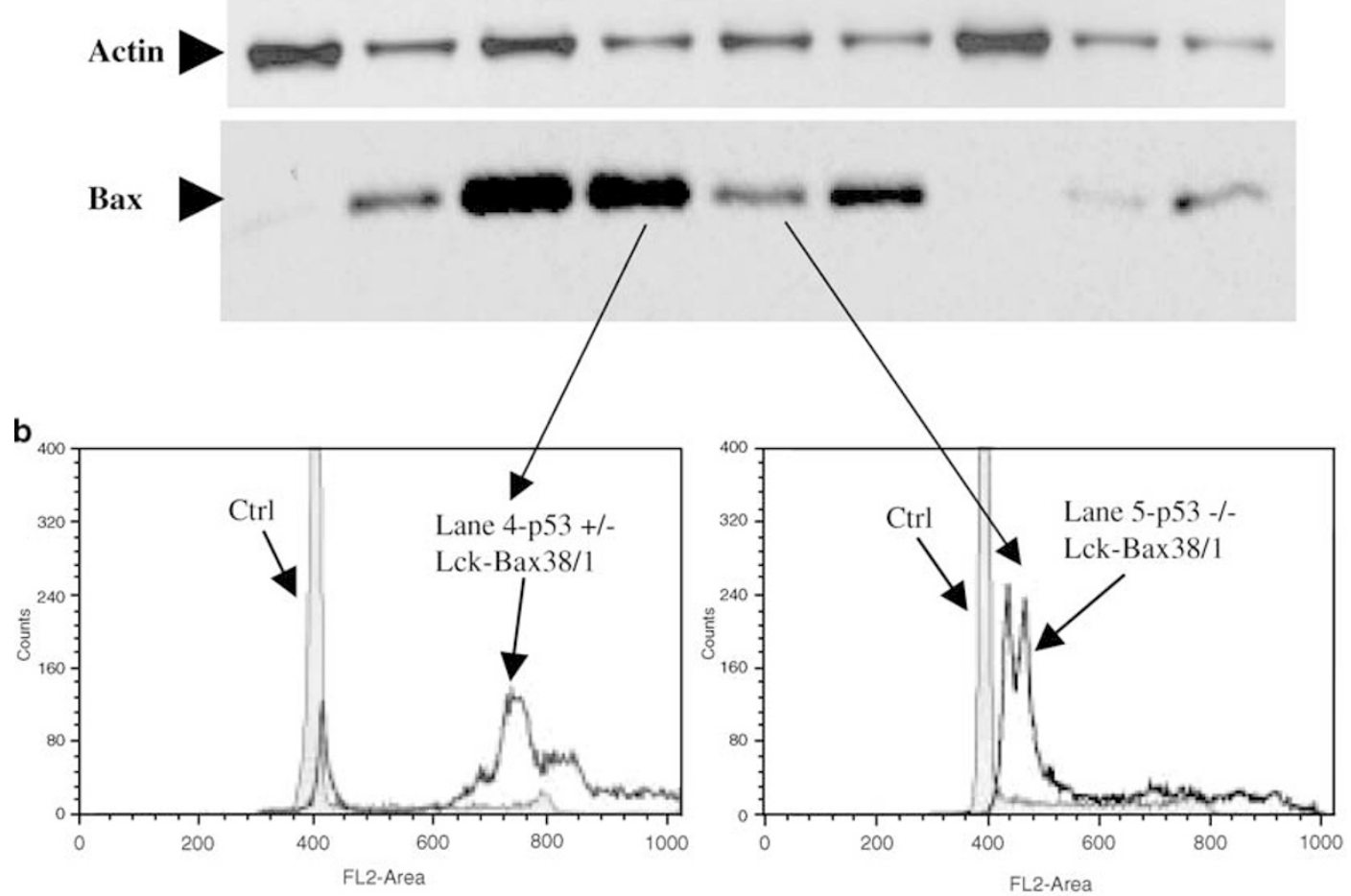

Figure 5 Thymic tumors in Lck-Bax transgenic mice maintain Bax expression and demonstrate progressive aneuploidy. (a) Lysates were prepared from thymic tumors (T) or normal thymus $\mathrm{N}$ and analyzed by Western blot for Bax expression (top) or actin (bottom). Samples were prepared from Lck-Bcl-2 (+) tumors and multiple tumors from Lck-Bax transgenic mice (lines indicated by either 38 or 38/1). (b) DNA content analysis from two of the tumor samples shown in (a). Shaded histograms represent PI staining from control (diploid) animals performed in the same experiment. The bold line represents the tumor samples as indicated
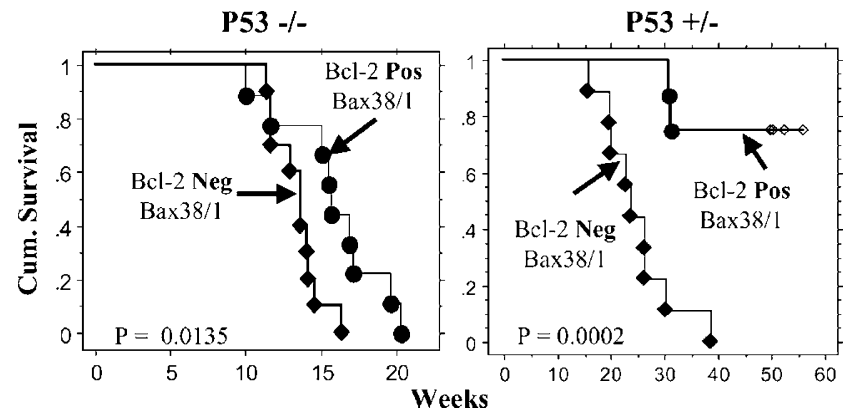

Figure 6 Bax and $\mathrm{Bcl}-2$ are antagonistic in tumor development. All mice expressed both copies of Lck-Bax (Bax38/1) and were either p53 - /- (left) or p53 $+/-$ (right). Tumor development with $(\checkmark)$ and without $(\mathbf{0})$ expression of Lck- $B C l-2$ is shown. The animals that survived for $>50$ weeks were censored and are indicated by open diamonds. The indicated $P$-value is based on the MantelCox logrank test (Statview)

for CIN as a number of cell lines are p53 deficient and do not display CIN. ${ }^{49}$ Furthermore, aneuploidy and CIN appear earlier in carcinogenesis than p53 mutations leading to the suggestion that $p 53$ exacerbates CIN but is neither necessary nor sufficient for it. ${ }^{48}$ Although Bax-induced lymphoma development is clearly accelerated by loss of $p 53$, the present data demonstrate that lymphoma development and CIN occur in animals with intact $p 53$. Of note, tumor development in LckBax38/1 was not accelerated in $p 53+/-$ mice. This suggest that loss of $p 53$ is not rate limiting in Lck-Bax38/1 transgenic mice with functional $p 53$.

Fanconi Anemia is a human inherited disease associated with chromosome instability that may be relevant to the results described here. ${ }^{50}$ Fanconi Anemia is an autosomal recessive disease associated with skeletal birth defects, anemia, hypogonadism, reduced fertility and cancer (leukemia and squamous cell carcinoma). Fanconi anemia is a genetic heterogeneous disease with at least eight proposed complementation groups based on cell fusion studies. Subsequently, seven genes (FANCA, C, D1, D2, E, F and G) have been identified and associated with Fanconi Anemia. ${ }^{51}$ Although unrelated at the sequence level, these gene products form a multiprotein nuclear complex whose function remains largely 


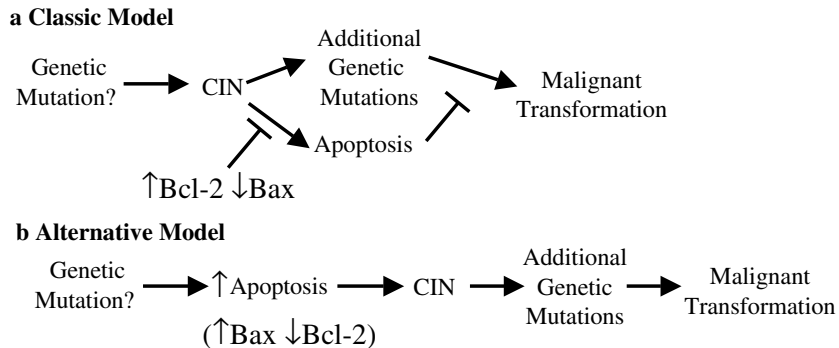

Figure 7 Models for relation betweens apoptosis and chromosomal instability. Current data support a model (a) in which chromosome instability (CIN) leads to increased apoptosis. In this model, inhibition of apoptosis by increase in Bcl-2 or decrease in Bax accelerate tumor development. The data described here support an alternative model (b) in which increased apoptosis (perhaps by changes in the $\mathrm{Bcl}-2$ family) may directly result in $\mathrm{CIN}$ and accelerate oncogenesis. It should be noted that these models are not mutually exclusive but instead suggest alternative means to malignant transformation

unknown. ${ }^{51}$ Mutations in Fanconi $\mathrm{A}$ and $\mathrm{C}$ are most common, and animal models now exist for these diseases. FANCC has been perhaps the most widely studied and several of these studies are worth noting relevant to our work. Like Bax, FANCC is localized predominantly to the cytoplasm and this localization may be crucial for its function. ${ }^{52,53}$ Furthermore, similar to overexpression of Bax, loss of function of FANCC leads to increased apoptosis in hematopoietic cells ${ }^{54-56}$ and germ cells. Therefore, both Fanconi Anemia and our Lck-Bax model are associated with increased apoptosis and CIN. One proposed common mechanism by which these pathways may lead to CIN may be via regulation of reactive oxygen species. Of note, both $\mathrm{FANCC}^{57}$ and $\mathrm{Bax}^{58}$ may regulate cell death through glutathione $S$ transferase. Although the significance of both these studies relative to the apoptotic function of the respective proteins remain controversial, the data demonstrate similarities between the two pathways, which may provide mechanistic insight into the pro-oncogenic activity of Bax.

Other studies have reported a connection between cell death and chromosome instability. Chinese hamster ovary cells that are unstable following radiation treatment show an increased susceptibility to apoptosis and increased oxidative stress. ${ }^{59,60}$ However, it was not clear in these studies whether increased susceptibility to apoptosis results from or perhaps precedes chromosome instability. Although alternative explanations exist, we favor a model in which Bax expression leads to CIN (directly or indirectly) while p53 functions to delete or inactivate cells that have rearranged or damaged DNA (Figure 7). Inhibition of Bax-induced lymphoma development by $\mathrm{BCl}-2$ supports a model in which increased sensitivity to apoptosis may lead to chromosome instability in developing $T$ cells. These results support other studies that have found a correlation between chromosome instability and apoptosis and suggest that increased sensitivity to apoptosis may precede and in some cases cause chromosome instability (Figure 7b).

Consistent with this model, other studies have found that thymic lymphomas develop in a setting of increased apoptosis. For example, Rag-1 and Rag-2 deficiency accelerated thymic lymphoma development in p53-/- mice. ${ }^{61} \mathrm{Rag}-1 / 2$ are essential for rearrangement of the T-cell receptor and are therefore necessary for T-cell development. ${ }^{62}$ Since thymocytes are unable to mature, the rate of apoptosis is increased because of what is sometimes referred to as death by neglect. Deficiency in an orphan steroid receptor results in increased apoptosis and T-cell lymphomas in mice. ${ }^{63}$ In humans, immunosuppressive therapy and corticosteroid may increase the risk of developing non-Hodgkins lymphoma. ${ }^{64}$ Taken together, these results suggest that genes (Bcl-2 family members) or factors that regulate apoptosis may regulate tumor development by controlling chromosome instability. They support a model in which increased sensitivity to apoptosis may precede and in some cases cause chromosome instability (Figure $7 b$ ).

\section{Materials and Methods}

\section{Materials and mice}

Lck-Bcl-2 and Lck-Bax transgenic mice were previously described and are genotyped by polymerase chain reaction (PCR) as previously described. ${ }^{29,65}$ P53-deficient mice obtained from Jackson Laboratory (Bar Harbor, ME, USA) were genotyped by PCR as previously described. ${ }^{33,66}$ Lck-Bax38 and Lck-Bax1 transgenic mice could be distinguished from one another because of the presence of a longer $3^{\prime}$ untranslated domain in the cDNA for Lck-Bax1. This results in a larger PCR product ( $\sim 150 \mathrm{bp})$ for Lck-Bax1 relative to Lck-Bax38.

\section{Tumor development studies}

All mice were maintained in the animal facility at the University of lowa under an approved protocol (ACURF \#9807226). Mice of the appropriate genotypes were mated to obtain animals for the tumor development studies. Upon entry into the tumor development study, animals were examined weekly for signs of illness or malignancy. Sick animals were monitored more frequently and euthanized when necessary to prevent unnecessary suffering. Control animals were monitored for up to 1 year and then killed for necropsy. As these animals did not show overt signs of disease, they were all censored from the analysis. When possible, necropsies were performed on dead animals to determine if the animals had gross evidence of tumors. Tumors were then confirmed by fixation with formalin and histological examination after $H \& E$ staining. All mice were maintained in the animal facility at the University of lowa (lowa City, IA, USA). Statistical analysis was performed with the StatView Program (SAS Institute Inc.) using Kaplan-Meier cumulative survival and the logrank (Mantel-Cox) test to determine the likelihood that differences in survival were significant between each of the indicated groups.

\section{Cell preparation and analysis}

Single-cell suspensions were prepared from the thymus by dispersing the organs between two glass slides in isotonic saline. In some experiments, red blood cells were removed by a 5 min incubation in hypotonic lysis buffer $\left(0.83 \% \mathrm{NH}_{4} \mathrm{Cl}, 10 \mathrm{mM}\right.$ Tris/pH 7.2). ${ }^{44}$ Viable cell counts were determined using a hemocytometer and trypan blue exclusion . Cells were cultured in RPMI supplemented with 10\% FCS, Pen-Strep, glutamine and 2-mercaptoethanol $(100 \mu \mathrm{M})$. Cell cycle analysis was performed by analyzing propidium iodide-stained nuclei on a flow cytometer equipped for doublet discrimination (FACScan or FACSCalibur from Becton Dickinson). Briefly, 1 million cells were pelleted and resuspended in $0.5 \mathrm{ml}$ of Krishan reagent prior to analysis by flow cytometry. ${ }^{67}$ Doublet 
events were gated out based on FL-2 area versus FL-2 width. Cellquest software (Becton Dickinson) was used for both acquisition and analysis.

\section{Cytogenetics}

Cytogenetics was performed with the assistance of the cytogenetics laboratory at the University of lowa. Briefly, thymocytes were isolated as described above and cultured briefly in colcemid (Gibco-BRL Cat\#15210040). The thymus organ was extracted from 8.9-week-old mice. The organ was minced and the thymocytes were treated with colcemid (Gibco-BRL Cat\#15210-040) at $1 \mu \mathrm{g} / \mathrm{ml}$ for $30 \mathrm{~min}$ at $37^{\circ} \mathrm{C}$. Following colcemid treatment, thymocytes were hypotonically swollen in $75 \mathrm{mM} \mathrm{KCl}$ and fixed in $3: 1$ acetic acid:methanol. Metaphase spreads were obtained by dropping fixed cells onto wet slides stored at $4^{\circ} \mathrm{C}$. The slides were stained with Giemsa prior to photography.

\section{Acknowledgements}

We thank Maurice Schuetz for reviewing tumor slides, Shiva Patil and Qining Qian for assistance with cytogenetics, Carla Lyons for assistance with manuscript preparation and Michael Cohen and Oscar Rohklin for critical review of the manuscript. This work was supported by Grant IN122T from the American Cancer society (to CMK). CMK is a Charles E Culpeper Medical Scholar and the work was supported by the Rockefeller Brothers Fund.

\section{References}

1. Gross A, McDonnell JM and Korsmeyer SJ (1999) BCL-2 family members and the mitochondria in apoptosis. Genes Dev. 13: 1899

2. Adams JM and Cory S (2001) Life-or-death decisions by the Bcl-2 protein family. Trends Biochem. Sci. 26: 61

3. Harris $\mathrm{MH}$ and Thompson CB (2000) The role of the Bcl-2 family in the regulation of outer mitochondrial membrane permeability. Cell Death Differ. 7 : 1182

4. MacCarthy-Morrogh L, Mouzakiti A, Townsend P, Brimmell M and Packham G (1999) Bcl-2-related proteins and cancer. Biochem. Soc. Trans. 27: 785

5. Wei MC, Zong WX, Cheng EHY, Lindsten T, Panoutsakopoulou V, Ross AJ Roth KA, MacCregor GR, Thompson CB and Korsmeyer SJ (2001) Proapoptotic $B A X$ and BAK: a requisite gateway to mitochondrial dysfunction and death. Science 292: 727

6. Zong WX, Lindsten T, Ross AJ, MacGregor GR and Thompson CB (2001) $\mathrm{BH} 3-$ only proteins that bind pro-survival $\mathrm{Bcl}-2$ family members fail to induce apoptosis in the absence of Bax and Bak. Genes \& Dev. 15: 1481

7. Cheng E, Wei MC, Weiler S, Flavell RA, Mak TW, Lindsten T and Korsmeyer SJ (2001) BCL-2, BCL-X-L sequester BH3 domain-only molecules preventing BAX- and BAK-mediated mitochondrial apoptosis. Mol. Cell 8: 705

8. Bakhshi A, Jensen JP, Goldman P, Wright JJ, McBride OW, Epstein AL and Korsmeyer SJ (1985) Cloning the chromosomal breakpoint of $t(14 ; 18)$ human lymphomas: clustering around $\mathrm{JH}$ on chromosome 14 and near a transcriptional unit on 18. Cell 41: 899

9. Cleary ML and Sklar J (1985) Nucleotide sequence of a t(14:18) chromosomal breakpoint in follicular lymphoma and demonstration of a breakpoint-cluster region near a transcriptionally active locus on chromosome 18. Proc. Natl. Acad. Sci. USA 82: 7439

10. Tsujimoto Y, Gorham J, Cossman J, Jaffe E and Croce CM (1985) The t(14:18 chromosome translocations involved in B-cell neoplasms result from mistakes in VDJ joining. Science 229: 1390

11. McDonnell TJ, Deane N, Platt FM, Nunez G, Jaeger U, McKearn JP and Korsmeyer SJ (1989) bcl-2-immunoglobulin transgenic mice demonstrate extended B cell survival and follicular lymphoproliferation. Cell 57: 79
12. Linette GP, Hess JL, Sentman CL and Korsmeyer SJ (1995) Peripheral T-cell lymphoma in Ickpr-bcl-2 transgenic mice. Blood 86: 1255

13. Miyashita T and Reed JC (1995) Tumor suppressor p53 is a direct transcriptional activator of the human bax gene. Cell 80: 293

14. Sidransky D and Hollstein M (1996) Clinical implications of the p53 gene. Ann. Rev. Med. 47: 285

15. Yin CY, Knudson CM, Korsmeyer SJ and Van Dyke T (1997) Bax suppresses tumorigenesis and stimulates apoptosis in vivo. Nature 385: 637

16. Shibata MA, Liu ML, Knudson MC, Shibata E, Yoshidome K, Bandey T, Korsmeyer SJ and Green JE (1999) Haploid loss of bax leads to accelerated mammary tumor development in C3(1)/SV40-TAg transgenic mice: reduction in protective apoptotic response at the preneoplastic stage. EMBO J., 18: 2692

17. Zhang L, Yu J, Park BH, Kinzler KW and Vogelstein B (2000) Role of BAX in the apoptotic response to anticancer agents. Science 290: 989

18. Eischen CM, Roussel MF, Korsmeyer SJ and Cleveland JL (2001) Bax loss impairs Myc-induced apoptosis and circumvents the selection of p53 mutations during Myc-mediated lymphomagenesis. Mol. Cel. Biol. 21: 7653

19. Rampino N, Yamamoto H, lonov Y, Li Y, Sawai H, Reed JC and Perucho M (1997) Somatic frameshift mutations in the bax gene in colon cancers of the microsatellite mutator phenotype. Science 275: 967

20. LeBlanc JLD, Vargolomeev E, Totpal K, Morlan J, Schow P, Fong S, Schwall R, Sinicropi D and Ashkenazi A (2002) Tumor-cell resistance to death receptorinduced apoptosis through mutational inactivation of the proapoptotic Bcl-2 homolog Bax. Nat. Med. 8: 274

21. Murphy KL, Kittrell FS, Gay JP, Jager R, Medina D and Rosen JM (1999) $\mathrm{Bcl}-2$ expression delays mammary tumor development in dimethylbenz(a)anthracene-treated transgenic mice. Oncogene 18: 6597

22. de la Coste A, Mignon A, Fabre M, Gilbert E, Porteu A, Van Dyke T, Kahn A and Perret C (1999) Paradoxical inhibition of c-myc-induced carcinogenesis by Bcl2 in transgenic mice. Cancer Res. 59: 5017

23. Meterissian SH, Kontogiannea M, Al-Sowaidi M, Linjawi A, Halwani F, Jamison $B$ and Edwardes $\mathrm{M}$ (2001) Bcl-2 is a useful prognostic marker in Dukes' B colon cancer. Ann. Surg. Oncol. 8: 533

24. Buglioni S, D'Agnano I, Cosimelli M, Vasselli S, D'Angelo C, Tedesco M, Zupi G and Mottolese M (1999) Evaluation of multiple bio-pathological factors in colorectal adenocarcinomas: independent prognostic role of p53 and Bcl-2. Int. J. Cancer 84: 545

25. Manne U, Myers RB, Moron C, Poczatek RB, Dillard S, Weiss H, Brown D, Srivastava S and Grizzle WE (1997) Prognostic significance of bcl-2 expression and p53 nuclear accumulation in colorectal adenocarcinoma. Int. J. Cancer 74: 346

26. Ofner D, Riehemann K, Maier H, Riedmann B, Nehoda H, Totsch M, Bocker W, Jasani B and Schmid KW (1995) Immunohistochemically detectable bcl-2 expression in colorectal carcinoma - correlation with tumour stage and patient survival. Br. J. Cancer 72: 981

27. Kaklamanis L, Savage A, Whitehouse R, Doussis-Anagnostopoulou I, Biddolph S, Tsiotos P, Mortensen N, Gatter KC and Harris AL (1998) Bcl-2 protein expression: association with p53 and prognosis in colorectal cancer. Br. J. Cancer 77: 1864

28. Silvestrini R, Veneroni S, Daidone MG, Benini E, Boracchi P, Mezzetti M, Difronzo G, Rilke F and Veronesi U (1994) The bcl-2 protein - a prognostic indicator strongly related to p53 protein in lymph node-negative breast cancer patients. J. Nat. Cancer Inst. 86: 499

29. Knudson CM, Johnson GM, Lin Y and Korsmeyer SJ (2001) Bax accelerates tumorigenesis in p53-deficient mice. Cancer Res. 61: 659

30. Hogarth LA and Hall AG (1999) Increased BAX expression is associated with an increased risk of relapse in childhood acute lymphocytic leukemia. Blood 93: 2671

31. Bairey O, Zimra Y, Shaklai M, Okon E and Rabizadeh E (1999) Bcl-2, Bcl-X, Bax, and Bak expression in short- and long-lived patients with diffuse large Bcell lymphomas. Clin. Cancer Res. 5: 2860

32. Hanahan D and Weinberg RA (2000) The hallmarks of cancer. Cell 100: 57

33. Jacks T, Remington L, Williams BO, Schmitt EM, Halachmi S, Bronson RT and Weinberg RA (1994) Tumor spectrum analysis in p53-mutant mice. Curr. Biol. 4: 1

34. McCurrach ME, Connor TMF, Knudson CM, Korsmeyer SJ and Lowe SW (1997) Bax-deficiency promotes drug resistance and oncogenic transformation by attenuating p53-dependent apoptosis. Proc. Natl. Acad. Sci. USA, 94: 2345 
35. Yamamoto $\mathrm{H}$, Itoh $\mathrm{F}$, Fukushima $\mathrm{H}$, Adachi $\mathrm{Y}$, Itoh $\mathrm{H}$, Hinoda $\mathrm{Y}$ and Imai $\mathrm{K}$ (1999) Frequent Bax frameshift mutations in gastric cancer with high but not low microsatellite instability. J. Exp. Clin. Cancer Res. 18: 103

36. Meijerink JPP, Mensink EJBM, Wang K, Sedlak TW, Sloetjes AW, Dewitte T, Waksman G and Korsmeyer SJ (1998) Hematopoietic malignancies demonstrate loss-of-function mutations of BAX. Blood 91: 2991

37. Gil J, Yamamoto H, Zapata JM, Reed JC and Perucho M (1999) Impairment of the proapoptotic activity of Bax by missense mutations found in gastrointestinal cancers. Cancer Res. 59: 2034

38. Tai YT, Lee S, Niloff E, Weisman C, Strobel T and Cannistra SA (1998) BAX protein expression and clinical outcome in epithelial ovarian cancer. J. Clin. Oncol. 16: 2583

39. Krajewski S, Blomqvist C, Franssila K, Krajewska M, Wasenius VM, Niskanen E, Nordling S and Reed JC (1995) Reduced expression of proapoptotic gene $\mathrm{BAX}$ is associated with poor response rates to combination chemotherapy and shorter survival in women with metastatic breast adenocarcinoma. Cancer Res. 55: 4471

40. Xie X, De Angelis P, Clausen OPF and Boysen M (1999) Prognostic significance of proliferative and apoptotic markers in oral tongue squamous cell carcinomas. Oral Oncol. 35: 502

41. Sturm I, Petrowsky H, Volz R, Lorenz M, Radetzki S, Hillebrand T, Wolff G, Hauptmann S, Dorken B and Daniel PT (2001) Analysis of p53/BAX/p16 (ink4a/CDKN2) in esophageal squamous cell carcinoma: high BAX and p16 (nk4a/CDKN2) identifies patients with good prognosis. J. Clin. Oncol. 19: 2272

42. Ong YL, McMullin MF, Bailie KEM, Lappin TRJ, Jones FGC and Irvine AE (2000) High bax expression is a good prognostic indicator in acute myeloid leukaemia. Br. J. Haematol. 111: 182

43. Brady HJ, Gil-Gomez G, Kirberg J and Berns AJ (1996) Bax alpha perturbs T cell development and affects cell cycle entry of T cells. EMBO J. 15: 6991

44. Linette GP, Li Y, Roth KA and Korsmeyer SJ (1996) Crosstalk between cell death and cell cycle progression: Bcl-2 regulates NFAT-mediated activation. Proc. Natl. Acad. Sci. USA 93: 9545

45. O'Reilly LA, Huang DC and Strasser A (1996) The cell death inhibitor Bcl-2 and its homologues influence control of cell cycle entry. EMBO J. 15: 6979

46. O'Reilly LA, Harris AW and Strasser A (1997) bcl-2 transgene expression promotes survival and reduces proliferation of CD3-CD4-CD8- $T$ cell progenitors. Int. Immunol. 9: 1291

47. Huang DC, O'Reilly LA, Strasser A and Cory S (1997) The anti-apoptosis function of Bcl-2 can be genetically separated from its inhibitory effect on cell cycle entry. EMBO J. 16: 4628

48. Lengauer C, Kinzler KW and Vogelstein B (1998) Genetic instabilities in human cancers. Nature 396: 643

49. Lengauer C, Kinzler KW and Vogelstein B (1997) Genetic instability in colorectal cancers. Nature 386: 623

50. Wright EG (1999) Inherited and inducible chromosomal instability: a fragile bridge between genome integrity mechanisms and tumorigenesis. J. Pathol. 187: 19

51. Joenje $\mathrm{H}$ and Patel KJ (2001) The emerging genetic and molecular basis of Fanconi anaemia. Nat. Rev. Genet. 2: 446
52. Wolter KG, Hsu YT, Smith CL, Nechushtan A, Xi XG and Youle RJ (1997) Movement of Bax from the cytosol to mitochondria during apoptosis. J. Cell Biol. 139: 1281

53. Youssoufian H (1996) Cytoplasmic localization of fac is essential for the correction of a prerepair defect in Fanconi anemia group c cells. J. Clin. Invest. 97: 2003

54. Rathbun RK, Christianson TA, Faulkner GR, Jones G, Keeble W, O’Dwyer M and Bagby GC (2000) Interferon-gamma-induced apoptotic responses of Fanconi anemia group C hematopoietic progenitor cells involve caspase 8dependent activation of caspase 3 family members. Blood 96: 4204

55. Rathbun RK, Faulkner GR, Ostroski MH, Christianson TA, Hughes G, Jones G, Cahn R, Maziarz R, Royle G, Keeble W, Heinrich MC, Grompe M, Tower TA and Bagby GC (1997) Inactivation of the Fanconi-anemia group C gene augments interferon-gamma-induced apoptotic responses in hematopoietic cells. Blood 90: 974

56. Haneline LS, Broxmeyer HE, Cooper S, Hangoc G, Carreau M, Buchwald M and Clapp DW (1998) Multiple inhibitory cytokines induce deregulated progenitor growth and apoptosis in hematopoietic cells from fac $(-/-)$ mice. Blood 91: 4092

57. Cumming RC, Lightfoot J, Beard K, Youssoufian H, O'Brien PJ and Buchwald $M$ (2001) Fanconi anemia group C protein prevents apoptosis in hematopoietic cells through redox regulation of GSTP1. Nat. Med. 7: 816

58. Kampranis SC, Damianova R, Atallah M, Toby G, Kondi G, Tsichlis PN and Makris AM (2000) A novel plant glutathione S-transferase/peroxidase suppresses Bax lethality in yeast. J. Biol. Chem. 275: 29207

59. Limoli CL, Hartmann A, Shephard L, Yang CR, Boothman DA, Bartholomew J and Morgan WF (1998) Apoptosis, reproductive failure, and oxidative stress in Chinese hamster ovary cells with compromised genomic integrity. Cancer Res. 58: 3712

60. Limoli CL, Kaplan MI, Corcoran J, Meyers M, Boothman DA and Morgan WF (1997) Chromosomal instability and its relationship to other end points of genomic instability. Cancer Res. 57: 5557

61. Nacht $M$ and Jacks $T$ (1998) $V(D) J$ recombination is not required for the development of lymphoma in p53-deficient mice. Cell Growth Differ. 9: 131

62. Mombaerts $P$, lacomini J, Johnson RS, Herrup $K$, Tonegawa $S$ and Papaioannou VE (1992) Rag-1-deficient mice have no mature $B$ and $T$ lymphocytes. Cell 68: 869

63. Uedo E, Kurebayashi S, Sakaue M, Backlund M, Koller B and Jetten AM (2002) High incidence of T-cell lymphomas in mice deficient in the retinoid-related orphan receptor ROR $\gamma$. Cancer Res. 62: 901

64. Cerhan JR, Wallace RB, Folsom AR, Potter JD, Sellers TA, Zheng W and Lutz CT (1997) Medical history risk factors for non-Hodgkins lymphoma in older women. J. Nat. Cancer Ins. 89: 314

65. Knudson CM and Korsmeyer SJ (1997) Bcl-2 and Bax function independently to regulate cell death. Nat. Genet. 16: 358

66. Lowe SW, Schmitt EM, Smith SW, Osborne BA and Jacks T (1993) p53 is required for radiation-induced apoptosis in mouse thymocytes. Nature 362: 847

67. Krishan A (1990) Rapid DNA content analysis by the propidium iodidehypotonic citrate method. Methods Cell Biol. 33: 121 